\title{
A case of pheochromocytoma presenting with cardiac manifestation: case report
}

\author{
Akbar Molaei ${ }^{1,2}$, Vahideh Abarzadeh-Bairami ${ }^{2}$ and Seyyed-Reza Sadat-Ebrahimi ${ }^{1 *}$ (D)
}

\begin{abstract}
Background: Pheochromocytomas are rare tumors originating in chromaffin cells which predominantly are located in adrenal glands. Sustained or paroxysmal hypertension $(H T)$ is the most frequent sign of pheochromocytoma. In some cases, it is associated with the classic triad including episodic headaches, sudoresis, and tachycardia; however, we present a case of pheochromocytoma with first presentation of cardiomyopathy.

Case presentation: The authors describe a rare case of a pheochromocytoma which was first presented with cardiomyopathy in a 7-year-old patient. The patient was admitted with malaise, abdominal pain, polydipsia, and myalgia. Further evaluations revealed hyperglycemia, mild dehydration and sinus tachycardia but no HT. Echocardiography demonstrated some of the signs of cardiomyopathy which was incorrectly diagnosed as viral myocarditis. The patient was discharged with this diagnosis but he presented again with HT crisis a few months later. A diagnosis of pheochromocytoma was assigned after the evaluation of the HT secondary causes. The diagnosis was confirmed by metanephrine assay and the tumor was localized in the adrenal gland using the abdominal MRI.

Conclusion: Pheochromocytoma can present itself with normotensive cardiomyopathy. Therefore, the possibility of pheochromocytoma should be considered in patients with cardiomyopathy especially in those with positive familial history.
\end{abstract}

Keywords: Pheochromocytoma, Cardiomyopathy, Hypertension, Cardiac involvement, Case report

\section{Background}

Pheochromocytoma is a rare neuroendocrine tumor that produces catecholamines and other neuropeptides, originating mainly in the adrenal gland medulla. It has an annual incidence of approximately 0.8 per 100,000 person-years [1]. The majority of cases are sporadic, but $10-25 \%$ of the cases can be associated with genetic syndromes such as Von Hippel-Landau (VHL) disease, type 1 neurofibromatosis and multiple endocrine neoplasia type 2 (MEN 2) [2]. Sustained or paroxysmal hypertension (HT) is the most frequent sign of pheochromocytoma. In some cases, it is associated with the classic triad including episodic headaches, sudoresis, and tachycardia [3]. Cardiovascular complications due to adrenergic stimulation can potentially be fatal, emphasizing the

\footnotetext{
* Correspondence: Sadatr@tbzmed.ac.ir

${ }^{1}$ Cardiovascular Research Center, Shahid Madani Heart Center, Tabriz University of Medical Sciences, Tabriz, Iran

Full list of author information is available at the end of the article
}

importance of timely diagnosis and effective therapeutic strategy. In the current case report, we describe a rare case of a pheochromocytoma which was first presented with cardiomyopathy in a 7-year-old patient. The case is reported after obtaining the permission of the institutional review board.

\section{Case presentation}

A 7-year-old boy with a negative history for any particular diseases presented with malaise and abdominal pain to the emergency room. These symptoms had appeared since 1 month before admission and were gradually worsen in the last 2 weeks. The patient had also developed polydipsia and myalgia. On admission, the patient was afebrile (body temperature [BT], 36.7), with a pulse rate (PR) of $200 / \mathrm{min}$ [150/min after hydration], a respiratory rate of $25 / \mathrm{min}$, blood pressure (BP) of $105 / 65 \mathrm{mmHg}$, and blood sugar (BS) of 256 $\mathrm{mg} / \mathrm{ml}$. Oral mucosa was dehydrated but other examinations revealed no significant findings. Laboratory test results are 
reported in Table 1 . The patient was admitted to endocrinology service with the diagnosis of new-onset diabetes mellitus type 1 (DM1). BS was controlled (fasting BS = 100-110 $\mathrm{mg} / \mathrm{dl}$, postprandial $\mathrm{BS}=115-140 \mathrm{mg} / \mathrm{dl}$ ) by administration of insulin. Electrocardiogram showed normal sinus tachycardia. On the transthoracic echocardiography, there was a mild pericardial effusion, left ventricular (LV) ejection fraction (EF) of 30-35\%, mild LV hypertrophy and LV diameter of $33 \mathrm{~mm}$. Considering sinus tachycardia, echocardiography findings, white blood cell count (WBC) of $17,200 / \mu \mathrm{l}$, and erythrocyte sedimentation rate (ESR) of 60 , the cardiologist suggested a diagnosis of cardiomyopathy due to viral myocarditis. Treatment with dopamine $(1 \mu \mathrm{g} / \mathrm{kg})$, milrinone ( $50 \mu \mathrm{g} / \mathrm{kg}$ stat and $5 \mu \mathrm{g} / \mathrm{h}$ infusion), furosemide ( $1 \mathrm{mg} / \mathrm{kg}$ two times daily), captopril (6.25 $\mathrm{mg}$ two times daily), and

Table 1 Laboratory tests results at first admission

\begin{tabular}{|c|c|c|}
\hline \multirow[t]{2}{*}{ Laboratory tests } & \multicolumn{2}{|l|}{ Time } \\
\hline & Result in admission & $\begin{array}{l}\text { Result before } \\
\text { discharge }\end{array}$ \\
\hline \multicolumn{3}{|l|}{ Urine } \\
\hline WBC & $2-3$ & \\
\hline $\mathrm{RBC}$ & $1-2$ & \\
\hline Bacteria & Negative & \\
\hline Glucose & +++ & \\
\hline Crystal amurate & Many & \\
\hline Ketone & Negative & \\
\hline \multicolumn{3}{|l|}{ Blood (serum) } \\
\hline WBC $\left(1000 / \mathrm{mm}^{3}\right)$ & 17.2 & 10.9 \\
\hline Lmyph (\%) & 34.4 & 34.5 \\
\hline Neut (\%) & 58.8 & 54.7 \\
\hline $\mathrm{Hb}(\mathrm{g} / \mathrm{dl})$ & 13.3 & 12.4 \\
\hline Plt $\left(1000 / \mathrm{mm}^{3}\right)$ & 561 & 510 \\
\hline BS (mg/dl) & 180 & \\
\hline Urea (mg/dl) & 25 & \\
\hline $\begin{array}{l}\text { Creatinine (mg/ } \\
\text { dl) }\end{array}$ & 0.6 & \\
\hline $\mathrm{Na}(\mathrm{mg} / \mathrm{dl})$ & 136 & \\
\hline $\mathrm{K}(\mathrm{mg} / \mathrm{dl})$ & 4.2 & \\
\hline ESR & 60 & 60 \\
\hline $\begin{array}{l}\text { C-reactive } \\
\text { protein }\end{array}$ & ++ & \\
\hline Blood culture & $\begin{array}{l}\text { Negative } \\
\text { (in three times repetitions) }\end{array}$ & \\
\hline \multicolumn{3}{|c|}{ Venus blood gas analysis } \\
\hline $\mathrm{PH}$ & 7.48 & \\
\hline PCO2 & 25.6 & \\
\hline $\mathrm{PO} 2$ & 66.4 & \\
\hline $\mathrm{HCO} 3$ & 18.8 & \\
\hline
\end{tabular}

WBC white blood cells count, $R B C$ Red blood cells count, $\mathrm{Hb}$ Hemoglobin, ESR Erythrocyte sedimentation rate carvedilol (6.25 mg two times daily) was initiated and insulin therapy was continued with the same dose. BP monitoring was conducted but the patient was normotensive. PR was gradually reduced from 140 to $150 / \mathrm{min}$ to $105-100 / \mathrm{min}$ in a few days.. WBC was decreased from 17,200 to 10,940/ $\mu \mathrm{l}$ (Table 1). The patient was discharged and the following medications were prescribed to be taken at home: captopril (12.5 mg every $12 \mathrm{~h}$ ), carvedilol (6.25 mg every $12 \mathrm{~h}$ ), insulin glargine (4 units each night) and insulin aspart ( 2 units before each meal). In the outpatient visits, the patient had adequate BS control, normal BP, and was asymptomatic except for a mild malaise and inadequate weight gain.

After 21 months the patient was admitted again due to HT (BP, 189/140 mmHg), nausea, sudoresis, and malaise. No headache, tremor, pallor, dyspnea, and generalized weakness were seen in the patient before admission. The BP was reduced to $140 / 80 \mathrm{mmHg}$ and transferred to ICU. The patient developed a headache during his stay in ICU.

Doppler ultrasonography of renal veins and arteries was performed but no significant pathologies were detected. Considering the positive familial history of pheochromocytoma in his uncle and clinical suspicion for pheochromocytoma, the urinary levels of metanephrine, epinephrine, norepinephrine, and vanillylmandelic acid were assessed. Hormonal assays revealed elevated serum and urinary normetanephrine, norepinephrine, and metanephrines (Table 2). Furthermore, a metaiodobenzylguanidine (MIBG) scan and abdominal MRI were performed. Abdominal MRI confirmed the presence of a $35 \times 25 \times 16 \mathrm{~mm}$ mass at the left adrenal gland, which was hyper-signal on T2WI and hypo-signal on T1WI. The right adrenal gland was unremarkable (Fig. 1). MIBG scintigraphy identified bilateral uptake increase in the regions of adrenal glands. Normal uptake was seen in other parts of the body. Bilateral MIBG avid areas in both adrenal glands were suggestive for pheochromocytoma (Fig. 2). In transthoracic echocardiography, a mild $\mathrm{LVH}$ and a mild tricuspid regurgitating were reported. LVEF was 55\% (Fig. 3).

Treatment with oral $\mathrm{Ca}$ channel blocker, beta-blockers was initiated (amlodipine $5 \mathrm{mg}$ and metoprolol $50 \mathrm{mg}$ ) and followed by losartan ( $25 \mathrm{mg}$ daily) to adequately normalize BP.

The left side adrenal tumor was removed by surgery and the right side was examined but remained intact. Histopathological evaluations confirmed the diagnosis of pheochromocytoma. After surgery, the patient's medications were tapered and discontinued. He remained normotensive and BS was in a normal range. The symptoms faded away and the patient was discharged with no further medications but was advised to return regularly for outpatient visits.

During 1 year follow-up after discharge, the patient remained asymptomatic. $\mathrm{He}$ was not receiving any 
Table $\mathbf{2}$ Laboratory tests results at second admission

\begin{tabular}{|c|c|c|}
\hline Laboratory tests & Result & Reference value \\
\hline \multicolumn{3}{|l|}{ Urine } \\
\hline Urinary Norepinephrine ( $\mu \mathrm{g} / 24$ h) & 490 & $<90$ \\
\hline Urinary Epinephrine ( $\mu \mathrm{g} / 24 \mathrm{~h})$ & 13.14 & $<20$ \\
\hline Urinary metanephrines ( $\mu \mathrm{g} / 24 \mathrm{~h})$ & 58 & $25-312$ \\
\hline Urinary normetanephrines ( $\mu \mathrm{g} / 24 \mathrm{~h}$ ) & 1133.2 & $<600$ \\
\hline WBC & $1-2$ & $<5$ \\
\hline RBC & $0-1$ & $0-1$ \\
\hline Bacteria & Negative & \\
\hline Crystal amurate & Few & \\
\hline Glucose & Negative & \\
\hline Protein & Negative & \\
\hline \multicolumn{3}{|l|}{ Blood (serum) } \\
\hline Cortisol $(\mu \mathrm{g} / \mathrm{dl})$ & 18.2 & $4.5-25.0$ \\
\hline Renin $(\mathrm{mlU} / \mathrm{ml})$ & $>500$ & $\begin{array}{l}\text { 2.8-39.9 (supine } \\
\text { posture) }\end{array}$ \\
\hline Aldosterone (ng/dl) & 62.8 & $\begin{array}{l}\text { 3.7-31 (supine } \\
\text { posture) }\end{array}$ \\
\hline TSH (mlU/L) & 4.2 & $0.4-6.21$ \\
\hline FT4 (ng/dl) & 9.5 & $6.4-15$ \\
\hline
\end{tabular}

WBC white blood cells count, $R B C$ Red blood cells count, TSH Thyroid releasing hormone, FT4 Free thyroxine

medications. The BS was in the normal range and the patient was normotensive.

\section{Discussion}

We described a clinical case of a 7-year-old boy with the first presentation of cardiomyopathy due to pheochromocytoma. Pheochromocytoma is symptomatic in nearly half of the patients. These symptoms are typically paroxysmal. One-half of the symptomatic patients have paroxysmal hypertension; however, nearly 5 to $15 \%$ of patients present with normal BP $[1,4]$. As a very rare incidence, pheochromocytoma is associated with cardiomyopathy. This phenomenon is ascribed to the excessive release of catecholamines mainly epinephrine and norepinephrine, which stimulate adrenergic receptors. It occurs with similar pathophysiology to that in stress-induced (takotsubo) cardiomyopathy [5]. These patients are reported to present with pulmonary edema; however, no pulmonary edema was detected in our patient [6]. It is suggested to perform echocardiography for symptomatic patients. Although, it is usually normal in asymptomatic patients, including those with asymptomatic hypertension [7]. A study on 26 consecutive patients with pheochromocytoma reported that echocardiographic evaluations in $62.1 \%$ of the patients were normal but $27.6 \%$ of the patients had concentric LV hypertrophy with normal LV systolic function and $10.3 \%$ had LV systolic dysfunction. In only three symptomatic patients, echocardiography revealed catecholamine cardiomyopathy with transient LV dysfunction [8]. Our patient in the first admission was diagnosed as cardiomyopathy due to viral myocarditis. This diagnosis could explain most of the patient's signs and symptoms. The clinical presentations of myocarditis are greatly variable ranging from subclinical disease, to fatigue, chest pain, arrhythmias, heart failure, cardiogenic shock, and sudden death. Sinus tachycardia is the most common arrhythmia in patients with myocarditis which was also present in our patient. Moreover, our patient's echocardiographic findings including LV dilatation without hypertension, systolic dysfunction, and mild pericardial effusion were all suggestive of myocarditis. Although, this diagnosis could explain most of our observations in this patient, we understood that pheochromocytoma as an important differential diagnosis should have been considered in this case. Furthermore, at the first admission, our patient presented an abnormal glucose level which was diagnosed

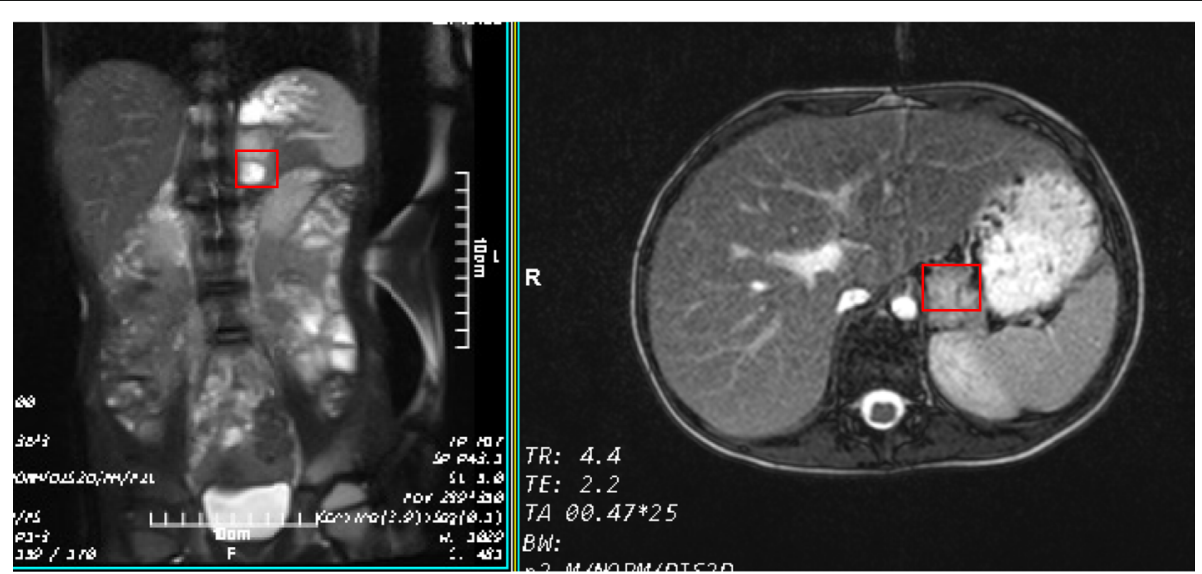

Fig. 1 Abdominal magnetic resonance imaging (MRI) which depicts a left adrenal gland nodule (red boxes, over $3 \mathrm{~cm}$ diameter) 


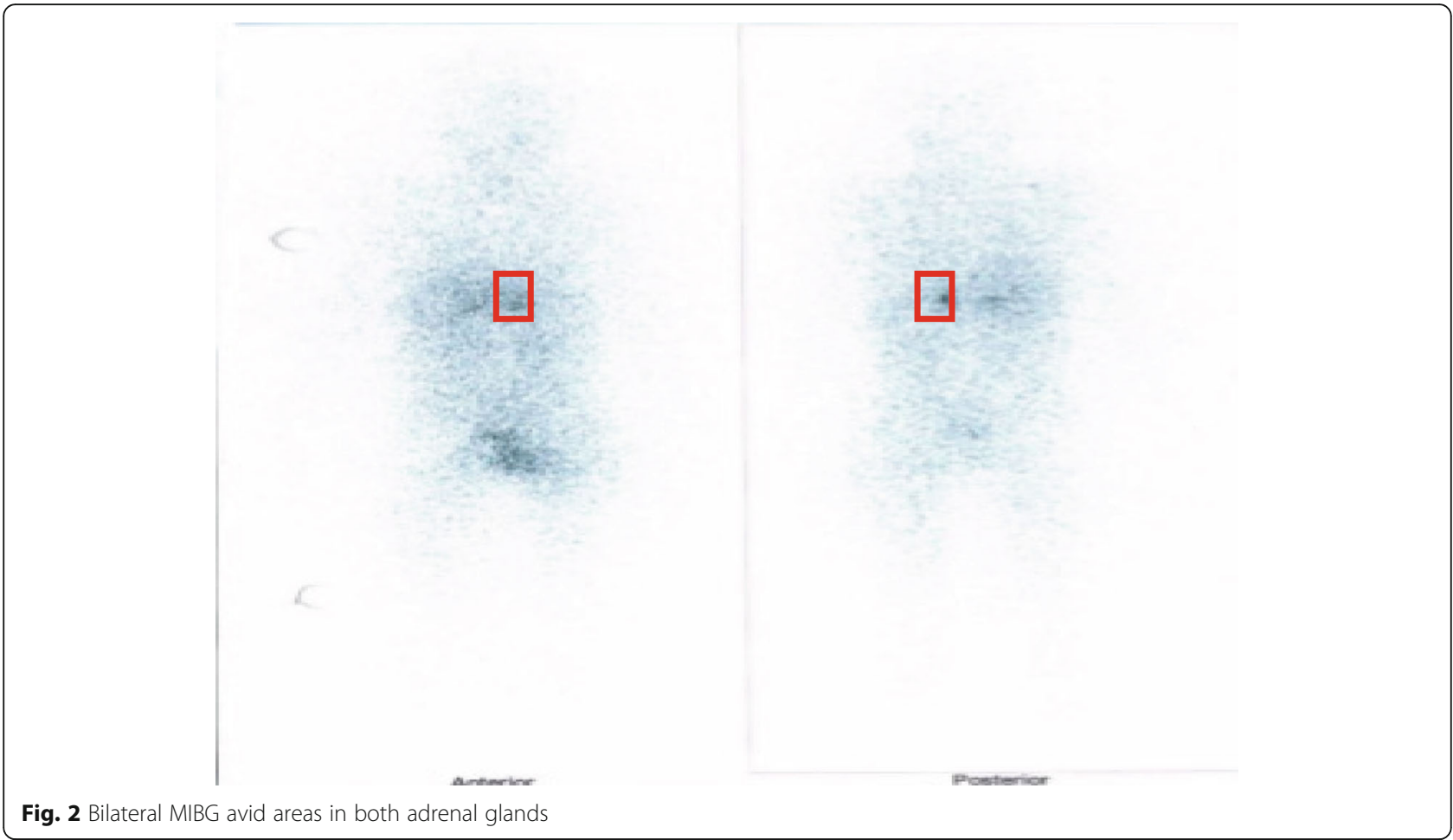

incorrectly as DM1, though, it was a carbohydrate metabolism impairment that was directly related to the catecholamine excess due to pheochromocytoma.

The exact mechanism of cardiomyopathy despite normal blood pressure in pheochromocytoma patients is not clearly explained in the literature. We assumed that possibly undetected transient hypertension crisis had induced cardiac failure and dilatation in this patient; however, the drop in noradrenaline secretion and heart

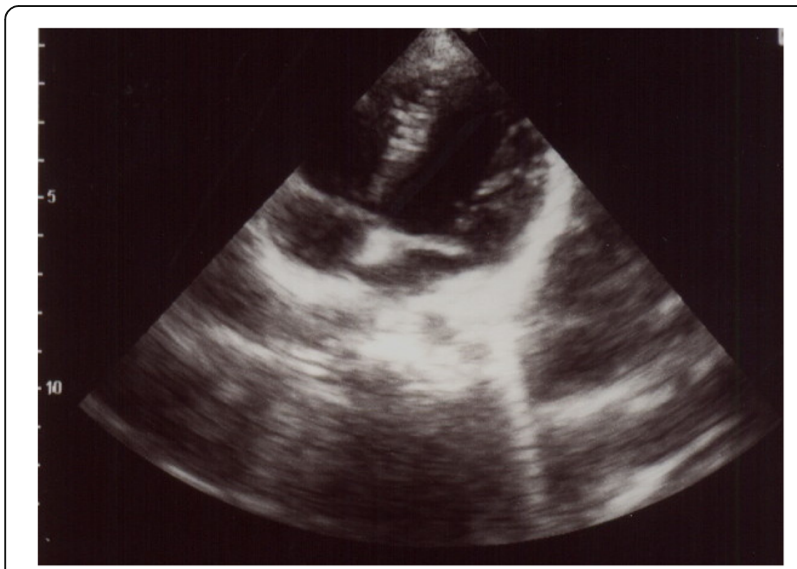

Fig. 3 Transthoracic echocardiography revealed normal fourchamber size and function, except for a mild LVH and mild tricuspid regurgitating with an LVEF of 55\% failure have made that we only detect normal blood pressure between the episodes of hypertension crisis.

The first presentation of this patient was in some way ambiguous and challenging. However, the symptoms in the second presentation were more suggestive of pheochromocytoma in particular hypertension. Considering the age of our patient, the most probable etiologies for hypertension would be renal/renovascular, endocrine diseases or aortic coarctation. Renal/renovascular etiologies are the most common in this age; however, the absence of abdominal murmurs, normal renal function and Doppler ultrasonography of the renal arteries rolled out such diagnosis. Aortic coarctation was rolled out using transthoracic echocardiography. Therefore, pheochromocytoma remained the most probable endocrine disease which may cause hypertension in this case. Our patient had elevated renin and aldosterone levels. This phenomenon is reported to occur in some patients with pheochromocytoma $[9,10]$.

After clinical suspicion of a pheochromocytoma, tumor localization is essential with proper imaging such as abdominal CT or MRI and I131-MIBG scintigraphy. Approximately 85 to $90 \%$ of catecholamine releasing tumors are intra-adrenal but about 10 to $15 \%$ of them are extra-adrenal and are referred to as catecholaminesecreting paragangliomas. Different therapeutic options are available for each category. Though, the best choice for our patient was surgery after BP normalization with $\mathrm{Ca}$ Blocker and B-adrenergic drugs. Following resection 
of catecholamine secreting mass, the patients became asymptomatic and the laboratory tests were normal. Moreover, no further medication was indicated.

Long-term follow-up is required for all patients with pheochromocytoma due to the possibility of recurrence. Considering the dramatic response of our patient to treatment and normal results of medical examinations and laboratory tests until 1 year, he has apparently a favorable prognosis; however, the possibility of tumor relapse still necessities long-term follow-up [11].

\section{Conclusion}

Pheochromocytoma is one of the secondary causes of HT that can be treated surgically. However, it can present itself with normotensive cardiomyopathy. Therefore, the possibility of pheochromocytoma should be considered in patients with cardiomyopathy especially in those with positive familial history.

\section{Abbreviations}

HT: Hypertension; VHL: Von Hippel-Landau disease; MEN 2: Multiple endocrine neoplasia type 2; BT: Body temperature; PR: Pulse rate; BP: Blood pressure; BS: Blood sugar; DM1: Mellitus type 1; LV: Left ventricular; EF: Ejection fraction; WBC: White blood cell count; ESR: Erythrocyte sedimentation rate; ICU: Intensive care unit; MIBG: Metaiodobenzylguanidine

\section{Acknowledgements}

We would like to thank the members of the pediatrics reasearch center of the Tabriz University of Medical Sciences for their kind help that greatly improved the manuscript.

\section{Authors' contributions}

Collected the data: AM, VA, SRSE. Wrote the draft manuscript: SRSE, VA. Revised and edited the final manuscript: AM. Approved the manuscript: AM, VA, SRSE. All authors read and approved the manuscript.

\section{Funding}

This study was funded by none.

\section{Availability of data and materials}

All Data and material collected during this study are available from the corresponding author upon reasonable request.

\section{Ethics approval and consent to participate}

Ethical clearance was sought from medical ethics committee of Tabriz University of Medical Sciences, Tabriz, Iran. Written informed consent was obtained from the parents of the patient.

\section{Consent for publication}

Written informed consent was obtained from both parents of the patient to publish this case report.

\section{Competing interests}

The authors declare that they have no competing interests.

\section{Author details}

${ }^{1}$ Cardiovascular Research Center, Shahid Madani Heart Center, Tabriz University of Medical Sciences, Tabriz, Iran. ${ }^{2}$ Pediatric Health Research Center, Tabriz Children Hospital, Tabriz University of Medical Sciences, Tabriz, Iran.

Received: 25 April 2020 Accepted: 9 June 2020

Published online: 17 June 2020

\section{References}

1. Young, W. F. (2019). "Clinical presentation and diagnosis of pheochromocytoma." Retrieved 30/1/2020, 2020.
2. Gimenez-Roqueplo AP, et al. An update on the genetics of paraganglioma, pheochromocytoma, and associated hereditary syndromes. Horm Metab Res. 2012;44(05):328-33.

3. Reisch N, et al. Pheochromocytoma: presentation, diagnosis and treatment. J Hypertens. 2006;24(12):2331-9.

4. Baguet J-P, et al. Circumstances of discovery of phaeochromocytoma: a retrospective study of 41 consecutive patients. Eur J Endocrinol. 2004;150(5): 681-6.

5. Kassim T, et al. Catecholamine-induced cardiomyopathy. Endocrine Practice. 2008;14(9):1137-49.

6. Sibal $L$, et al. Phaeochromocytomas presenting as acute crises after beta blockade therapy. Clin Endocrinol. 2006;65(2):186-90.

7. Park J-H, et al. Prevalence and patterns of left ventricular dysfunction in patients with pheochromocytoma. J Cardiovasc Ultrasound. 2011;19(2):7682.

8. Shub C, et al. Echocardiographic findings in pheochromocytoma. Am J Cardiol. 1986:57(11):971-5.

9. Haase $\mathrm{M}$, et al. Excessive catecholamine secretion and the activation of the renin-angiotensin-aldosterone-system in patients with Pheochromocytoma: a single center experience and overview of the literature. Horm Metab Res. 2017:49(10):748-54.

10. Vetter $\mathrm{H}$, et al. Renin and aldosterone secretion in pheochromocytoma: effect of chronic alpha-adrenergic receptor blockade. Am J Med. 1976;60(6): 866-71.

11. Alface MM, et al. Pheochromocytoma: clinical review based on a rare case in adolescence. Case Reports. 2015;2015:bcr2015211184.

\section{Publisher's Note}

Springer Nature remains neutral with regard to jurisdictional claims in published maps and institutional affiliations.
Ready to submit your research? Choose BMC and benefit from:
- fast, convenient online submission
- thorough peer review by experienced researchers in your field
- rapid publication on acceptance
- support for research data, including large and complex data types
- gold Open Access which fosters wider collaboration and increased citations
- maximum visibility for your research: over $100 \mathrm{M}$ website views per year
At $\mathrm{BMC}$, research is always in progress.
Learn more biomedcentral.com/submissions 